\title{
Effects of Shortage of Nurses at St. Dominic's Mission Hospital, Ndola, Zambia
}

\author{
Article by Elizabeth Njovu \\ Nursing, Texila American University \\ E-mail: njovulisa@yahoo.com
}

\begin{abstract}
The shortage of nurses is a problem that is common everywhere in the world. Nurses form the largest number in the healthcare system and play a significant role in providing direct patient care. Considering the importance of the role of nurses in the healthcare system, it is important to investigate how nursing shortage affects the quality of patient care, nurses' job satisfaction and their work stress. Zambia is not an exception to this scourge, most hospitals face this challenge of nursing shortage. One such Hospital is St. Dominic's Mission Hospital located in the outskirts of Ndola.

There is a confirmed positive relationship between nurse shortage and workload. There is also a significant positive relationship between workload and the quality of patient care. Furthermore, a negative relationship was observed between workload and the quality of patient care. In addition, this study calculates the mean effect of emotional intelligence of these factors, and a significant correlation is found between emotional intelligence and workload as well as work stress. It can be said that in Zambia, nursing shortage Influences the workload of the employee, finally affecting the quality of patient care. In addition, the study recognized the capability of nurses to manage their emotions as well as emotions of others, which has increased their tolerance to control psychological stress in performing their duty. This study confirms that nurse's emotional intelligence act as a partial moderating variable for job outcomes of nurses.

Background: The shortage of nursing staff is a great challenge worldwide, it affects many nations in the world. With this shortage, patients are suffering because the healthcare workforce is not prepared to deal with their health needs. In each country, the shortage of nurses is as a result of a number of factors that ultimately cause a decrease in the quality of health care given. However, little is known about the global causes of a shrinking professional nurse workforce.

Main objective: To assess the effects that shortage of nurses has on the care of patients and on the few nurses providing care at St. Dominic's Mission Hospital, Zambia.

Method: A cross-sectional study was conducted to assess and identify the effects of the shortage of nurses on care of the patient as well as on the few nurses providing care. Data was collected using the self-structured questionnaire with closed and open ended questions. Purposeful sample of 20 nurses participated.

Results: 20 nurses participated: 15 females and 5males; aged between 21 to 50 years. Majority (90\%) diploma Holders and are registered nurses. Findings reveal that (100\%) are aware of the shortage of nurses at the Hospital, (89\%) feel the impact of the shortage of nurses has on them. (70\%) indicated that shortage of nurses compromises the quality of patients care, 55\% of the participants had knowledge on the nurse-patient ratio for the general medical ward while $45 \%$ did not. $20 \%$ indicated that poor Human resource planning by administration has caused the shortage, while $75 \%$ indicated unrevised staff establishment and 5\% indicated that migration of nurses is the reason for nurse shortage at the hospital. $100 \%$ expressed that shortage of staff makes them stressed and work long hours.

Conclusion and recommendation: the participants' are very much aware of the shortage of nurses not only at St. Dominic's Mission Hospital but in other health care facility as well; they are determined to continue doing the best for the patients despite the shortage. It is therefore recommended that the
\end{abstract}


DOI: $10.21522 /$ TIJNR.2015.03.02.Art010

ISSN: $2520-3126$

administration at St. Dominic's Mission Hospital should urgently lobby for more nursing staff from the Ministry of Health.

Keywords: shortage, effects, nurses, compromised care, quality care, stressful environment, St. Dominic Mission Hospital.

\section{Introduction}

In every healthcare system nurses are the heart of the care of the patients and their shortage is very complex. The Shortage of nurses has an adverse impact on the health care systems around the world (Oulton, 2006). Kimball and O' Nell, 2002 defined the Nursing Shortage as a disproportion of supply and demand for nurses attributed to demographics, qualifications, availability and willingness to the work). However, Toh et al., 2012, described nursing shortage $\mathrm{i}$ as the inadequate number of nurses is to provide quality nursing care. Nurses in developed countries with distinctly healthcare systems have reported the same compromised quality of health care. The high spread nursing shortage and nurses' high turnover is a global issue ("The Global Shortage of Registered Nurses", 2013). The Shortage of Nurses in many hospitals and their impact, particularly on the compromised quality of care, has become common phenomenon. According to Douglas (2010), he suggested that administrators in the health care institutions need to collaborate to develop a workable and lasting solution for safe staffing.

Purpose and significance of the research: This research has been conducted to assess effects of shortage of nurses on the care of the patients and on the few nurses that provide care to the patients at St. Dominic's Mission Hospital.

When staff nurses are not adequate, the result is that quality nursing care is compromised and nurse burnout and stress is evident. The importance of this research has added to evidence based researches on effects of shortage of nurses on the patient care and the few nurses working. Findings are beneficial to both patients and the Human resource planners in planning for adequate Nursing Professionals, in improving quality nursing care and preventing stress and burnout of nurses. In the research done in March 2004 by the Agency for Healthcare Research and Quality on the impact that nursing shortage has on the patient outcomes, the study shows that hospitals with lower nurse staffing levels and fewer registered nurses tend to have higher rates of poor patient outcomes, nurse burnout and stress. This research was a reminder to the Human resource planners that for the quality patient care, adequate nurses need to be deployed in the hospitals and health care institutions in order to reduce on nurse burnout and nursing workload. According to Hurst (2002) he identified several criteria available to define whether the level and number of nurse staffing are enough to address the needs of patients and nurse staff herself. Some of the criteria identified includes: nurse's level of education, number of hospital beds, Size of the word, status of patients acute or chronic, the time required for individual nursing interventions and bed occupancy. Duffield et al., 2009 described Nursing workload as being influenced by the time spend by patients on wards. However a many studies on nursing workload and patient safety uses nurse-patient ratio as the measure of nursing workload.

Problem to be solved: The shortage of nurses in the health institutions has remain the major challenge and problem in most countries especially in developing countries, exposing the few nurses that are working to work long hours under very difficult and stressful conditions, are fatigued and have less job satisfaction. Nurse shortage, has contributed to the compromised care of patient. The nurse shortage mainly has been caused by few nurses being deployed by the Ministry of Health, unrevised establishment in most health facilities, nurse migration in search for greener pastures, fewer nurses being trained because of fewer nursing schools and the increased disease pattern that demand more nursing care. According to the World Health Organization almost 4.3 million of shortage of nurses globally was estimated. Nurses are the heart of the health care institution and the quality of patients care depends on them.

Existing solution to the problem: The most effective solution in addressing the problem of nursing shortage is through retention and recruitment which remains the most important ways to achieve a long- 
term solution to the nursing shortage. Recruitment should be done in a more attractive way to make nursing professional appealing especially to younger people. The work environment for nurses should be redesigned in order to achieve job satisfaction. The other way to reduce the shortage of nurses and especially at St. Dominic's Mission Hospital is for the Hospital administrator through the Ministry of Health to revise the staff establishment which has remained the same for a long time even after the growing number of the population accessing services at the hospital. At St. Dominic's Mission Hospital, the administrator through Churches Health Association of Zambia (CHAZ) has taken initiative to train the community volunteers to do the basic nursing care on the patients to reduce the work load on the nurses. The community volunteers are able to do bed making, dump dusting, bathing and feeding of patients. According to the Mach 30, 2013 America Magazine entitled, Nurse Recruitment, Nursing Careers, it stated that without adequate number of nurses in the health care institutions, patient care and safety is compromised and while nurses themselves become overwhelmed, distressed, and dissatisfied. The patient-nurse ratios at St. Dominc's Mission Hospital and in many health facilities in Zambia has been so high (1:20). Many based evidence and efforts to reduce the shortage of nurses have been implemented by the hospital administrator. Different researchers have done different studies to find potential and lasting solutions for the nursing shortage as they examine its causes. Their researches findings give hope to maintain and improve the healthy environment that promotes safe, quality nursing care and initiates a professional avenue that is desirable by nurses. (Zurmehly, J. 2008)

\section{Background}

The Zambian Government has put in place a national health care syste, to service its's population of about 13 Million. The government's commitment to the objective of improving the quality of life of all Zambians has been demonstrated through its effort to improve health care delivery by reforming the Public Health Sector through the Health Reforms. In 1991, the Zambian government articulated radical health policy reforms characterized by a move from a strongly centralized health system in which the central structures provided support and national; guidance to the peripheral structures (CBoH 1991). These Health Reforms established government's commitment to improve the health of the population by progress towards achieving targets that were set. The Ministry of Health states that careful human resources is necessary in order to meet the health needs of the population (CBOH 1991).

The human resources in the Ministry of Health mainly comprise health proffesionals. Nurses comprise about $75 \%$ of all health care proffessionals in the health care system in the country (General Nursing Council of Zambia, 2004). This menas that Nurses who are the majority in the health care delivery system implement most of the health care programmes.

The Zambian health system has two (2) categories of nurses, namely the Registered Nurses and the enrolled Nurses. The levels of training differentiate the two (2) categories. The Enrolled Nurses undergo a two year (2) training programme and graduate with a Certificate. The Registered Nurses undergo a three (3) year training programme and graduate with a Diploma. They can then specialize locally in Registered Midwifery, Operating theatre Nursing and Mental Health Nursing (General Nursing Council of Zambia, 2004). The University of Zambia and many other private universities offers a Bachelor of Science degree programme for Registered Nurses who upon graduation are skilled to become researchers, educators, administrators, clinical specialists etc.

The Ministry of Health (2005) states that Zambia has around 10,000 nurses in practice as against a population of more than 10 millon, leaving a ratio of about 1 nurse to 1,000. With the increase in population, the Ministry of Health articulated the ratio to be 0.8 nurse to 1,000 . The ratio is in adequate to meet the health needs of the Zambian population. For some years it has been noted that most of our nurses are leaving the country for greener pastures in foreign countries. There are many reasons for the attrition of nurses in general and at St. Dominic's mission Hospital in particular. It is widelt believed that Britain, South Africa, USA and Australia are currently large drawers of Zambian nurses, who are well trained but 
DOI: $10.21522 /$ TIJNR.2015.03.02.Art010

ISSN: $2520-3126$

unable to make ends meet working at home. In 2004, it was noted that 2000 nurses in the UK General Nurses Council Register are Zambians, (Post News paper 2004).

St. Dominic's mission Hospital where the Study was conducted is a mission Hospital in the outskirts of Ndola. It has a bed capacity of 100 with a catchment area population of 15, 000(Table 1). According to the records, the establishment is supposed to have over 30 nurses but currently there are only about 16 nurses, leaving a balanc of about 14 , as shown in Figure 2. This has led to a situation where one nurse attends to a lot more patients.

Table 1. St. Dominic's mission hospital population

\begin{tabular}{|l|l|l|}
\hline \multicolumn{3}{|l|}{ ST. Dominic's Mission Hospital Population } \\
\hline Category & & YEAR 2017 \\
\hline Children under one year & 3.5252 & 15,000 \\
\hline Children under five years & 15.679 & 2,352 \\
\hline Children 5-14 years & 27.125 & 4,069 \\
\hline Children 0-15 years & 42.804 & 6,421 \\
\hline Women 15-45 years & 25.029 & 3,754 \\
\hline All adults 15 years + & 57.196 & 8,579 \\
\hline Total Male all ages & 49.531 & 7,430 \\
\hline Total Females all ages & 50.469 & 7,570 \\
\hline Total District Population & 100 & 15,000 \\
\hline
\end{tabular}

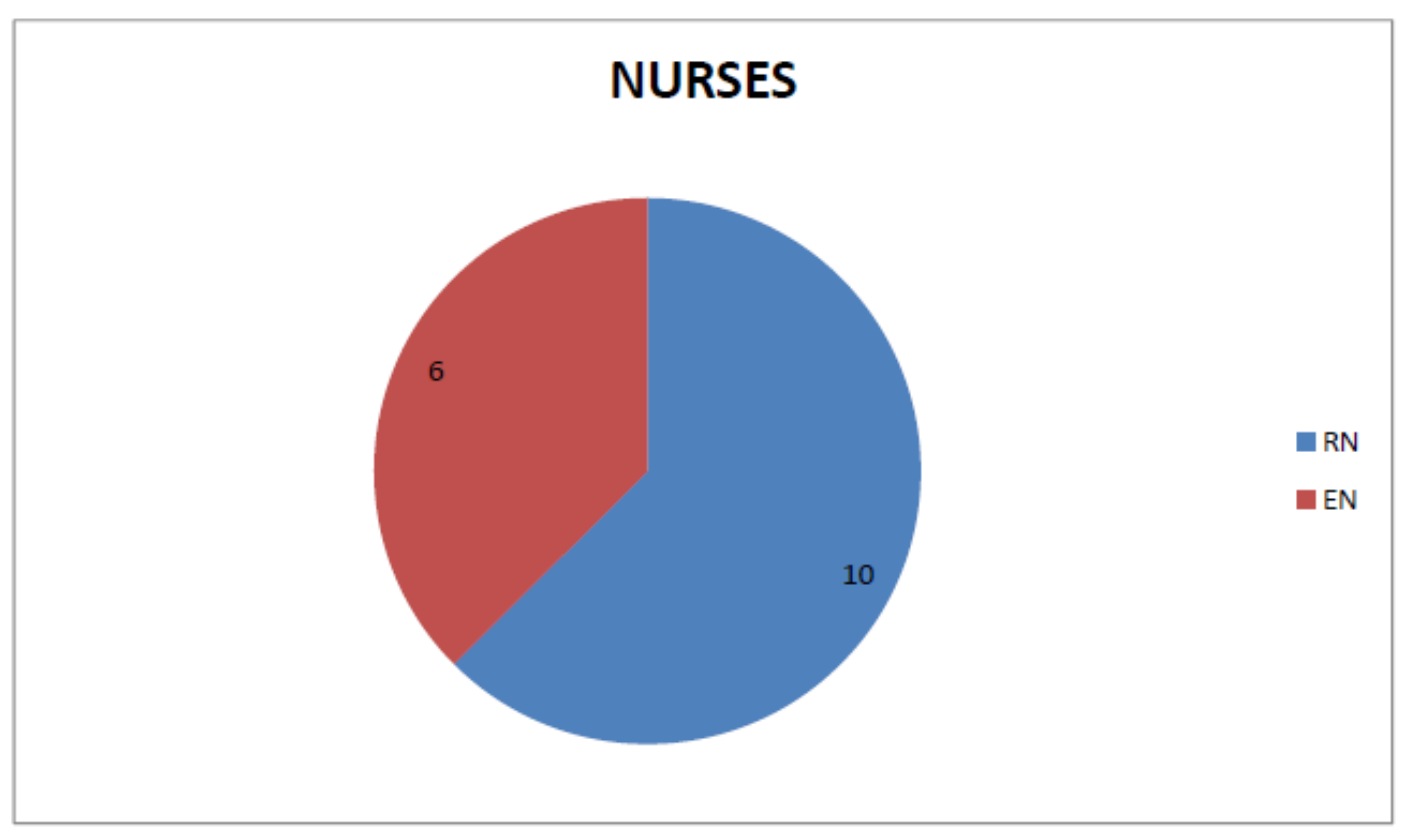

Figure 1.1. Number of nurses according to their positions 
Table 1.2

\begin{tabular}{|l|l|l|l|}
\hline Position & Establishment & Actual & Variance \\
\hline Registered Nurses & 12 & 10 & 2 \\
\hline Enrolled Nurses & 18 & 6 & 12 \\
\hline
\end{tabular}

For Sustained change and assurance of an adequate supply of nurses, solutions must be developed in several areas these include: staff retention methods that is improving the conditions of service and giving incentives, staff replacement by recruiting the conditions of service and also staff development through training, workshops, and improved image of nurses, hence this strudy needs to be carried out in order to identify the factors associated with the acute shortage of nurses at St. Dominic's Mission Hospital.

Study limitations: Study participants were only nurses; excluded other professionals and support staff. This could result in missing other key and rich information on effects of nursing shortage at St. Dominic's Mission Hospital.

Because of limited time and the busy schedule during data collection period, some missing responses in the questionnaire could not be followed up; hence important information could have been missed, to make the report richer

\section{Method used}

The research was conducted in May/June 2017. Data was collected at one point in time which was appropriate due to limited time and inadequate resources for the whole research. Collected data gave information of the effects of shortage of nurses on the care of the patient. Findings would assist administrators who do budgeting and planning for Human resource in identifying effects that nursing shortage has on the care of the patients while they plan and budget for nurse recruitment and make it a priority.

Purposive sampling, a type of non-probability sampling, which is extremely useful was used to obtain the information from nurses working at St. Dominic's Mission Hospital.

Self-administered structured questionnaire of both open and closed ended questions was used for Data collection. Questionnaires were hand delivered to 20 nurses and then hand collected, for confidentiality's sake; quality data verification was done. Collected Data consisted of Primary and secondary; primary data included; social demographic, respondents' characteristics of age and sex, marital status, and number of years in service which helped in assessing effects of shortage of nursing on the care of patients while secondary data consisted of the main topic of the research.

Strengths of data collection method: The self-structured questionnaire was given to the respondents once only and all respondent work at the same hospital, which made it cheaper and less time consuming. The respondent were eager to participate because the topic affects them and they have experience the effects of nurse shortage.

Limitations during data collection period: The distribution of the questionnaire was limited to nursing staff only and all of them working at the same hospital, this could have lead to some missing information and values to add to the richness of the research.

\section{Results}

20 nurses participated: 15 females and 5males; aged between 21 to 50 years. Majority (90\%) diploma Holders and are registered nurses. Findings reveal that (100\%) are aware of the shortage of nurses at the Hospital, (89\%) feel the impact of the shortage of nurses has on them. (70\%) indicated that shortage of nurses compromises the quality of patients care, $30 \%$ indicated that nursing shortage has caused the poor patient outcome, $55 \%$ of the participants had knowledge on the nurse-patient ratio for the general medical ward while $45 \%$ did not. $20 \%$ indicated that poor Human resource planning by administration has caused the shortage, while $75 \%$ indicated unrevised staff establishment and 5\% indicated that migration of nurses is the reason for nursing shortage at the hospital. $100 \%$ expressed that shortage of staff makes them 
DOI: $10.21522 /$ TIJNR.2015.03.02.Art010

ISSN: $2520-3126$

stressed and work long hours. 90\% indicated 1:35 as the nurse patient ratio of the medical ward at St. Dominic's mission hospital while $10 \%$ did not know the ratio. $100 \%$ of the participants recommended that the hospital establishment for nurses be revised and the Ministry of Health to deploy more nurses.

\section{Discussion}

Social demographic characteristics of study participants: 20 total number of study participants all of them nurses. Their age ranged from 21 to 50 years, majority were $21-35$ years. $55 \%$ of the study participants were married, reason being that, at this time they had completed their diploma course, as reflected by high number $90 \%$ of diploma holders and mostly as registered nurses $60 \%$; having worked between 1-5 years.

Participants' general information about effects of nursing shortage on patient care: Findings revealed that most participants are aware of the nursing shortage; they have experiences the effects this has on the patient as well as on themselves

Concerning the causes of nursing shortage the participants were able to elaborate at least 3 causes each. Mostly participants talked amongst themselves how the nursing shortage affects their work and quality of nursing care. Therefore, results shows adequate participants' general knowledge on nursing shortage, however there was need to update themselves on the standard nurse patient ratio $\mathrm{s}$ for different departments.

Without a sufficient number of nurses, patient care and safety may become compromised, while nurses themselves may be overwhelmed, distressed, and dissatisfied. High nurse-patient ratios has shown to that nurses are frustrated and experience job burnout, which is linked to higher turnover.

\section{Knowledge of participants towards nursing shortage}

Specific objectives on participants' nursing shortage knowledge level were: finding out whether the nursing levels were adequate, what effects nursing shortage has on the patient as well as the nurse. General knowledge on the nurse/patient ratio, causes of nursing shortage and what would be proper recommendations to the hospital administrator.

The findings indicated that most participants had adequate knowledge on all the aspects of the research objectives. Figure 3 illustrates the major effects of the shortage of nurses according to the respondents.

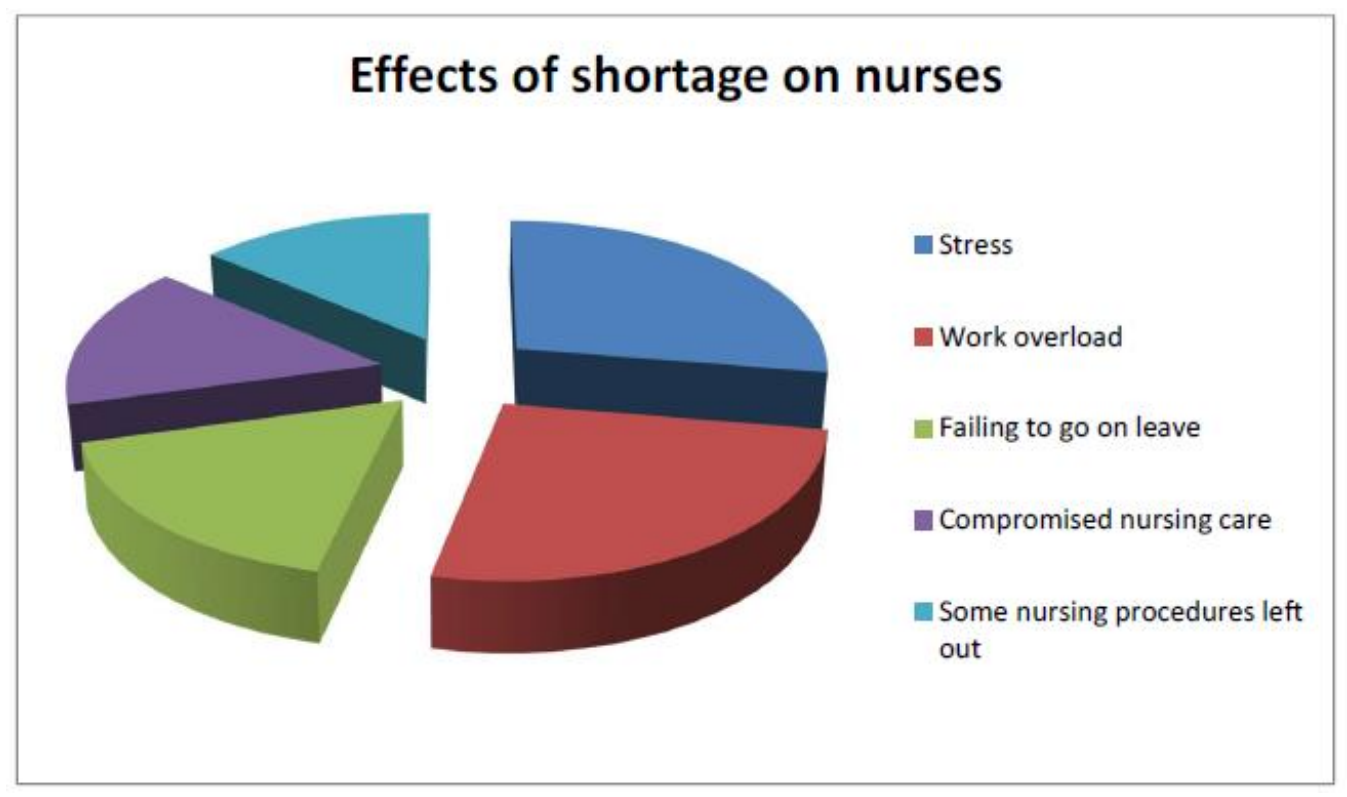

Figure 2. Major effects of shortage of nurses 


\section{Conceptual framework and variables}

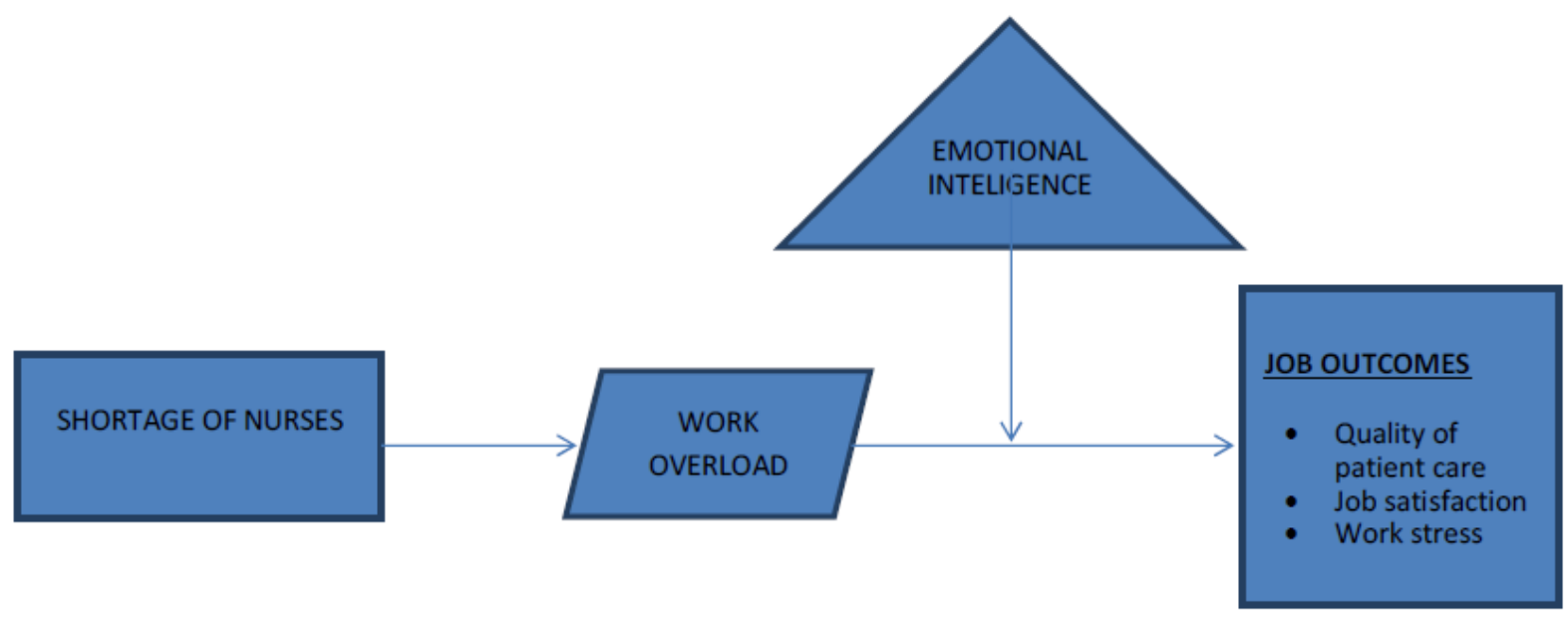

Figure 2.1. Conceptual framework

The following conceptual framework was developed to identify the relationships, if any, and the Impact among the related variables of the research. The following operational definitions of the study variables were developed and used in this study.

Table 2.2. Operational definitions of the variables

\begin{tabular}{|l|l|}
\hline Variable & Definition \\
\hline Nurses' Shortage & $\begin{array}{l}\text { The number of nurses is not enough to provide high quality of care as } \\
\text { compared to the professional standard }\end{array}$ \\
\hline $\begin{array}{l}\text { Quality of Patient } \\
\text { Care }\end{array}$ & $\begin{array}{l}\text { Delivering healthcare that fulfills the expressed or implied } \\
\text { requirements of a patient }\end{array}$ \\
\hline Job Satisfaction & $\begin{array}{l}\text { The degree to which individual feel positive or negative about their } \\
\text { jobs }\end{array}$ \\
\hline Work Stress & $\begin{array}{l}\text { The response people may experience when presented with work } \\
\text { demands and pressures that are not matched to their knowledge and } \\
\text { abilities and which challenge their ability to cope }\end{array}$ \\
\hline $\begin{array}{l}\text { Emotional } \\
\text { Intelligence }\end{array}$ & $\begin{array}{l}\text { The ability or skill of an individual to understand and influence the } \\
\text { emotions within themselves and those around them. }\end{array}$ \\
\hline
\end{tabular}

Source: Researchers based on literature survey.

Based on the above conceptual framework, the following hypotheses were developed.

- There is a positive relationship between shortage of nurses and workload.

- There is a negative relationship between workload and quality of patient care.

- There is a negative relationship between workload and nurses' job satisfaction.

- There is a positive relationship between workload and work stress. 
DOI: $10.21522 /$ TIJNR.2015.03.02.Art010

ISSN: $2520-3126$

Table 2.3. Self developed scales to measure the variables of the study

\begin{tabular}{|l|l|}
\hline VARIABLE & INDICATORS \\
\hline Workload & $\begin{array}{l}\text { Shift Duration } \\
\text { Overtime (Mandatory and Voluntary) } \\
\text { Busyness of the Ward } \\
\text { Floating to Nursing Units }\end{array}$ \\
\hline $\begin{array}{l}\text { Quality of Patient } \\
\text { Care }\end{array}$ & $\begin{array}{l}\text { Communicating with Nurse } \\
\text { Respect for patient values } \\
\text { Showing attention to the patient } \\
\text { Nurses' Competence }\end{array}$ \\
\hline Job Satisfaction & $\begin{array}{l}\text { Nature of the work } \\
\text { Work environment } \\
\text { Interpersonal relations } \\
\text { Career advancement }\end{array}$ \\
\hline Work Stress & $\begin{array}{l}\text { Nature of the work } \\
\text { Dealing with the staff } \\
\text { Work environment } \\
\text { Required knowledge and skills }\end{array}$ \\
\hline $\begin{array}{l}\text { Emotional } \\
\text { Intelligence }\end{array}$ & $\begin{array}{l}\text { Ability to work under pressure } \\
\text { Ability to manage stress } \\
\text { Ability to Control Own Impulses } \\
\text { Adaptation to Environment } \\
\text { Problem Solving Skills }\end{array}$ \\
\hline
\end{tabular}

\section{Workload}

Nursing workload is mainly influenced by the shortage of nurses and the number of patients staying in the ward. In Zambian healthcare setting, a nursing ward is where a large number of patients requiring care and lack of resources to provide care with inadequate number of nurses.

Nurses are midst of the system that requires them to work hard. Normally, hospital wards are overcrowded with large number of patients, bystanders and healthcare staff. It looks very busy, a chaotic and demanding environment for nurses to work in. Comparing large patient numbers do not increase the number of nurses and the roster remains the same. Therefore, the study results showed that the considerable number of nurses continued their duty to next shift. Some nurses indicated that their duty shift was often extended within the last month. This situation led nurses to do more overtime to make up minimum nurse workforce numbers. Considering the overtime done by nurses, they have done more voluntary overtime hours compared to the mandatory overtime. The increased workload of nurses leads to high possibility in nursing errors and delays. It was evident in this study that, increased workload has influenced both tasks delayed and tasks not completed. The working situation in the ward at St. Dominic's Mission Hospital highlighted that the nurses have limited time to interact with their patients. Because of the routine nursing tasks like medication, injections, referrals, blood transfusion that nurses have to undertake, they have not enough time to talk with patients. The significant number of nurses reported that they have less time available to deliver care, because they have to complete non-patient activities such as maintaining ward statistics, dietary, nursing administration, and housekeeping during the shift.

The study reveals that the several wards and units at the hospital have a steady increase in workload. 


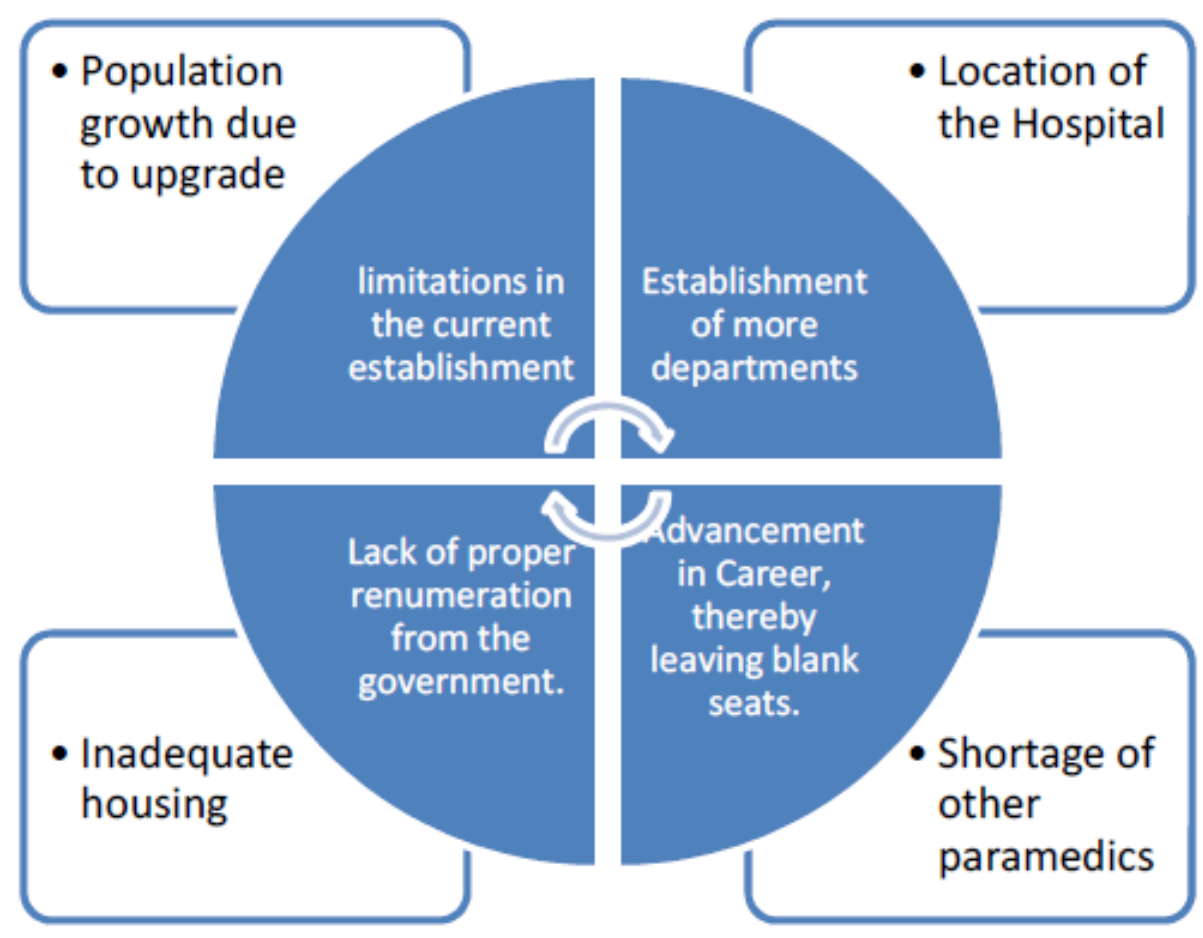

Figure 3. Causes of the shortage of nurses at st. dominic's mission hospital

The figure above illustrates the causes of the shortage of nurses at St. Dominic's Mission Hospital according to the staff who participated in the research via a questionnaire. The responses were varied but similar. The mast recurring cause was the shortage of adequate staff in other departments thereby forcing nurses to work in other fields other than what they were trained in. For example, some nurses work in the Pharmacy, focusing all their attention there due to lack of man power. The Hospital was recently upgraded to its current status as it used to be a health center; this has attracted more people and increased the population. Figure 3.1 illustrates the change in the workload of nurses now with the Hospital status as compared to when it used to be a health center. Due to lack of proper remuneration from the government, some nurses are changing careers thereby leaving a gap. The hospital is $25 \mathrm{~km}$ away from Ndola town center, this could be another reason why nurses are not motivated enough to transfer there. 
DOI: $10.21522 / \mathrm{TIJNR} .2015 .03 .02 . A r t 010$

ISSN: $2520-3126$

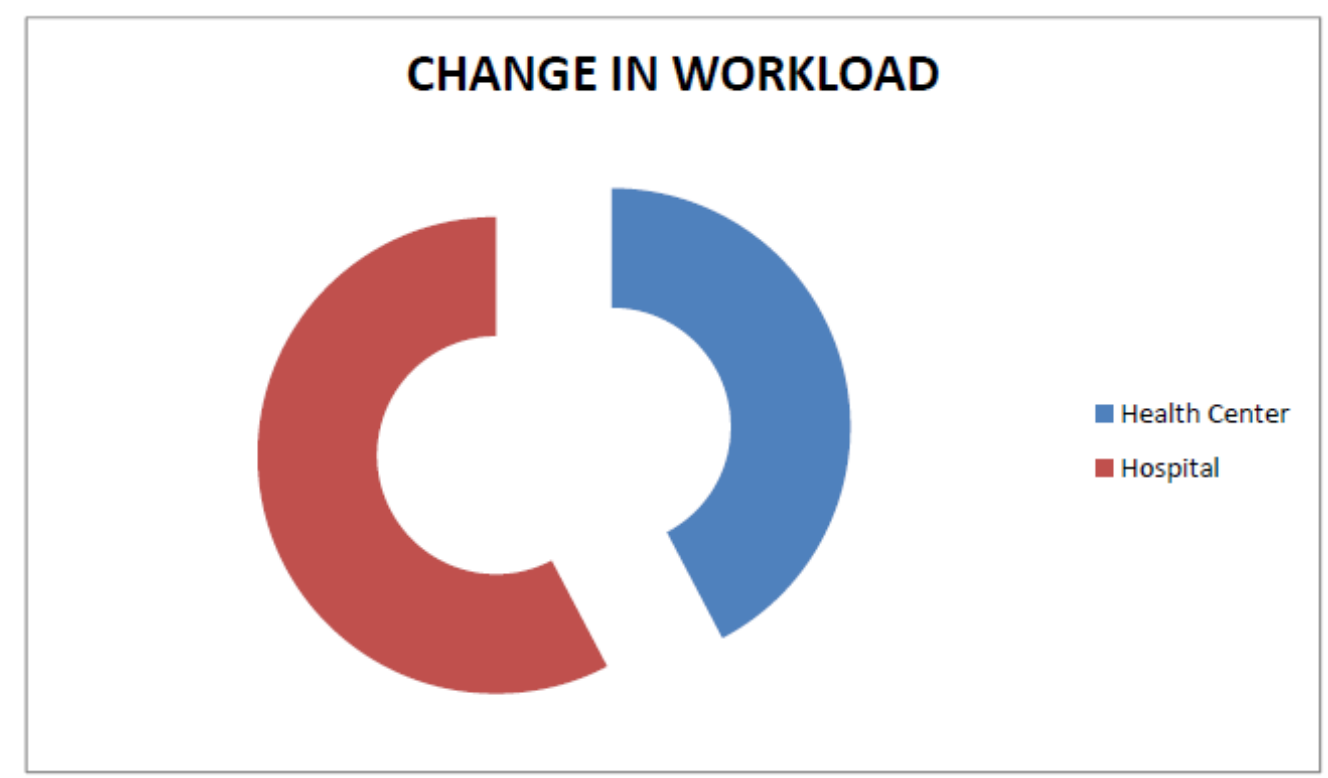

Figure 3.1. Change from health center to hospital effect on nurses's workload.

\section{Strategies for addressing the nursing shortage}

\section{There should be congruence between the different strategies}

Of course there will be various assertions and different estimations around nursing shortages and the extent of that shortage. But in evaluation of the policy initiatives in place to address the identified shortages, one does not expect there to be large discrepancies.

\section{Recruiting the future workforce}

Many experts recognize the need to increase funding for nursing education, directed toward nursing faculty as well as students. Subsidized training is seen as one way to increase the number of nurses. In addition, experts point to a need for changes in nursing training to better prepare the existing workforce to respond to changes in health care delivery. As options to strengthen nursing care, experts suggest training in gerontology, technology and information systems, clinical management, and variations in care delivery, as well as opportunities for further training for nurses at all stages in their careers.

Another way to address the nursing shortage would be to devote resources toward increasing Nurses' wages. This approach could affect recruitment as well as retention of nurses already in the workforce. Experts also suggest a need to improve the image of nursing. Strategies range from encouraging nurses to communicate more frequently about positive aspects of nursing to launching professional advertising campaigns promoting the profession.

\section{Retaining nurses in the workforce}

Strategies to improve nurses' retention are needed. Policies that improve the hospital's work environment are one set of important considerations. Another aspect of improving the work environment involves reorganizing nursing care to reduce paperwork and alter the types of work performed by nurses in order to increase the proportion of nursing time spent on patient care.

Redesigning the workplace in accord with ergonomic standards may become increasingly important to prevent injuries as the average age of the nurses' workforce increases.

Involving nurses in designing staffing and overtime policies also may result in higher satisfaction among nurses and better patient care. Unions representing nurses promote policies that reduce nurse workloads by increasing staffing to legislatively mandated nurse-to-patient ratios. Not all nurses or health 
professionals agree that mandated ratios are the most effective approach. Some suggest that nurse staffper-patient levels are best determined collaboratively with RNs at the hospital level.

It is also highly recommended that the Ministry of health assign more paramedics such as Pharmacy technicians to the hospital so that nurses are not forced to focus in other departments and there is equality in terms of man power.

The research findings reveal that nurses are consistently working long over stretched shifts due to staff shortage. This study reveals the nurse's workload directly influences to the quality of patient care. However, it does not influence significantly to the level of satisfaction and level of stress. The administration needs to customize their strategies for the recruitment and retention of nurses. The strategies should take into consideration the specific work settings that are experiencing negative nursing outcomes (poor patient care). The strategies should also aim to train that help nurses better manage their emotions.

A hospital is a group of healthcare professionals (primary care physicians, specialists and nurses) that work together as a team to coordinate care for patients. Nurses are mainly responsible for managing patients' health and providing care. They are set to play integral roles that include acting as care coordinators, communicators and quality improvement while providing care for patients. As a solution for nursing shortage prevailing in the country, health organizations can be reassigned the roles played by nurses only for patient-centered care. Nurses deployed for other services than direct patient care such as receptions and health education can be replaced with some other qualified personals. Many nurses are concerned that these substitutions could improve the quality of patient care. It is recommended that stress management training should be provided especially for nursing staff. The staff in management positions should emphasize the importance of interactions among nursing staff and between nurses and patients. The performance of emotional work was associated with fewer negative effects and with more positive psychological and social wellbeing for hospital nurses. Therefore the performance of emotional work should be considered to be a valuable coping strategy to be encouraged by hospital management.

\section{Conclusion}

Even absent nurse shortages, it would be costly for hospitals and long-term care providers to

Increase nurse staffing. Yet, recent evidence suggests that more nurses lead to better patient outcomes. Projected long-term shortages will create still greater cost and quality challenges. Without increased payments from public or private purchasers, health care institutions will most likely have to make tradeoffs between investing in staffing and pursuing other quality-improvement efforts. Little information is available to inform such decisions, which are likely to become more pressing in future years.

\section{References}

[1]. Bleich, M. R. (2011). IOM report, the future of nursing: Leading change, advancing health: Milestones and challenges in expanding nursing science. Research in Nursing \& Health.

[2]. Buerhaus, P. (1997). What is the harm in imposing mandatory hospital nurse staffing regulations? Nursing Economics.

[3]. Carayon, P., \& Gurses, A. (2005). Nursing workload and patient safety in intensive care units: a human factors engineering evaluation of the literature. Intensive critical Care Nursing.

[4]. Duffield, C., O’Braien, L., Diers, D., Aisbett, C., Aisbett, \& Homer, C. K. (2009). Nursing Workload and Staffing: Impact on Patients and Staff. University of Technology Sidney.

[5]. Greenglass, E. R., Burke, R. J., \& Moore, K. A. (2003). Reactions to increased workload: effects on professional efficacy of nurses. Apply Psycholog y: An International Review.

[6]. Kimball, B., \& O’Neil, E. (2002). Healthcare's Human Crisis.

[7]. Oulton, J. A. (2006). The Global Nursing Shortage: An Overview of Issues and Actions Policy Politics Nursing Practice. 
DOI: $10.21522 / \mathrm{TIJNR} .2015 .03 .02 . A r t 010$

ISSN: $2520-3126$

[8]. The Global Shortage of Registered Nurses: An Overview of Issues and Actions. (2013). Retrieved June 2, 2014, from http://www.icn.ch/publications/the-global-shortage-ofregistered-nurses-an-overview-of-issues-andactions/.

[9]. Toh, S. G., Ang, E., \& Devi, M. K. (2012). Systematic review on the relationship between the nursing shortage and job satisfaction, stress and burnout levels among nurses in oncology/hematology settings. International Journal of Evidence-Based Healthcare.

[10]. Weydt, A. P. (2009). Defining, analyzing, and quantifying work complexity. Creative Nursing. 